\title{
What Do CS Students Value in Industry Internships?
}

\author{
MIA MINNES, SHEENA GHANBARI SERSLEV, and OMAR PADILLA, \\ University of California San Diego
}

\begin{abstract}
Summer internships present an opportunity for Computer Science (CS) students to expand and test their skills in "the real world." These multi-faceted experiences call on students to use technical tools and critical thinking in collaboration with others to solve problems. There are many opportunities for learning and growth: which of these do students find most valuable? In this project, we collect and analyze open-ended reflections by undergraduate CS students at the conclusion of a summer internship. We see that students focus on technical skills, expanding professional networks, and the satisfaction of completing a product that will be of use to others. These insights help inform academic programs that support Computer Science students engaging in these internships and strengthen their connection to on-campus education.
\end{abstract}

CCS Concepts: • Social and professional topics $\rightarrow$ Computational science and engineering education; Employment issues; Model curricula; Computer science education; Informal education;

Additional Key Words and Phrases: Internships, professional identity, computer science identity, skills gap, personal and professional skills

ACM Reference format:

Mia Minnes, Sheena Ghanbari Serslev, and Omar Padilla. 2021. What Do CS Students Value in Industry Internships? Trans. Comput. Educ. 21, 1, Article 4 (March 2021), 15 pages.

https://doi.org/10.1145/3427595

\section{INTRODUCTION}

\subsection{CS Learning Outcomes}

Recent years have seen the influence of Computer Science (CS) grow in many aspects of modern life. More and more students are graduating with bachelor's degrees in US institutions [2, 32] and preparing to contribute to the growing tech economy. How can undergraduate education programs help prepare CS students to be successful professionals? Professional computer scientists must apply their technical proficiency to create products that have a broad impact on the world. Large-scale projects typically call for collaborations across large, multi-disciplinary teams. In a rapidly changing technology landscape, professionals are life-long learners. Undergraduate programs need to address this multifaceted nature of the profession in preparing our students. The most recent Association for Computing Machinery curriculum guidelines [19] identify the following desired characteristics of CS graduates: "Technical understanding of computer science, familiarity with common themes and principles, appreciation of the interplay between theory

Authors' address: M. Minnes, S. G. Serslev, and O. Padilla, University of California San Diego, 9500 Gilman Drive, La Jolla, California, 92093; emails: minnes@eng.ucsd.edu, \{sghanbari, opadilla\}@ucsd.edu.

Permission to make digital or hard copies of all or part of this work for personal or classroom use is granted without fee provided that copies are not made or distributed for profit or commercial advantage and that copies bear this notice and the full citation on the first page. Copyrights for components of this work owned by others than the author(s) must be honored. Abstracting with credit is permitted. To copy otherwise, or republish, to post on servers or to redistribute to lists, requires prior specific permission and/or a fee. Request permissions from permissions@acm.org.

(c) 2021 Copyright held by the owner/author(s). Publication rights licensed to ACM.

1946-6226/2021/03-ART4 \$15.00

https://doi.org/10.1145/3427595 
and practice, system-level perspective, problem solving skills, project experience, commitment to life-long learning, commitment to professional responsibility, communication and organizational skills, awareness of the broad applicability of computing, appreciation of domain-specific knowledge." In addition to core technical and general courses, out-of-classroom experiences can help students achieve some of these outcomes.

\subsection{Setting for This Project}

This article reports on the experiences of over 300 students at a public, research-intensive university in the western United States, who participated in full-time, on-site, paid internships lasting 8 to 14 weeks. During these internships, these students were enrolled in a companion course that aims to facilitate connections between students' work-based and academic learning. These connections revolved around three themes: technical development, personal and professional growth, and ethics and society. In open-ended reflections at the end of their internships, the students in this project reported on their internship accomplishments. Using qualitative analysis, we worked to answer the research question: In what ways do the themes of technical skills, interpersonal skills, ethics and society, and the academic and professional interface emerge when students reflect on their internships?

\section{BACKGROUND}

\subsection{Theoretical Grounding for Internships}

Internships can be broadly defined as experiential learning opportunities where students apply knowledge from their coursework in a guided, real-world setting [17, 26]. The Association of American Colleges \& Universities (AAC\&U) has identified internships as a high-impact educational practice [17]. The theoretical framework for including internships in educational programs is based on constructivist learning theories: that students build upon their own prior knowledge and construct learning through experiences. Dewey's theory of Learning by Doing supports the importance of integrating students' active engagement in course concepts [5]. Kolb's Experiential Learning framework [12] builds on these ideas, incorporating reflective observation as a key step after students engage in a concrete experience. These ideas inform several recent programs where students regularly reflect on their goals and experiences during self-guided internships $[3,16,18$, 30]. In the context of computer science, Lawrence-Fowler et al. highlight the importance of internship as a context for reflection and integration of academic learning with professional skills [14]. Lave and Wenger advocate for authentic learning experiences, where students engage in "legitimate peripheral participation" to advance from novice to expert in an apprenticeship model [13]. Internships are a vehicle for computer science students to engage in these experiences.

\subsection{What is an Internship?}

There is large variation in the definitions, motivations, nature, and quality of internships. Some internships are required of all students in a particular academic program, and are sometimes arranged by the educational institution itself. While internships typically occur outside the classroom setting, some programs use the term to refer to simulated experiences where students complete realistic projects, perhaps with a (real or imagined) client, within an on-campus course. Some internship experiences may be short, informal, and/or recurring. Others may be several months long, paid, full-time, and/or lead to postgraduate employment. These internship characteristics often correlate with the varying motivations that can underpin an internship program: a student may look to boost their related work experience, to explore possible career paths, and to better understand the climate at a potential workplace; employers may want to address skills gaps in the workforce, boost the recruiting pipeline, and more thoroughly vet potential recruits [29]. 
The student experience at an internship may be greatly influenced by the extent to which the work they need to do is clearly articulated, has value, and is well supervised [15]. In a 2017 literature review (including both published scholarly works and position papers by practitioners), the Center for Research on College-Workforce Transitions at the Wisconsin Center for Education Research found that much of the research on internships thus far is incomparable and inconclusive because of a lack of precision in the definition of the term [8]. In this article, internships are defined as paid, full-time, on-company-site engineering internships, where students are mentored as they work in novel situations on real-world projects. Using this definition, this project further restricts our attention to CS-oriented internships with a prescribed duration, intensity, and reflective structure.

\subsection{Connection with Industry}

In pre-professional programs such as CS, the interface between academic studies and industry requirements is important. Goddard's 1974 position paper suggests that internships and other exchanges between academic institutions and nearby companies can be mutually beneficial, both for allowing students to work on realistic (and, at the time, expensive) machines and problems and for companies to ensure a skilled workforce [7]. Early internship programs answered this call: Riehl [22] at Virginia Commonwealth University [22] and Ziegler [31] at SUNY, Binghamton each describe successful implementations. In both of these programs, students' company placements accompany a classroom component where they are coached on communication skills and share their experiences. Similar programs have been reported more recently, as well: Saltz and Oh describe an integrated internship-coursework model where students on extended internships take concurrent courses on communication and working with large-scale systems [25]; Oh [18] analyzed how students' learning strategies and behaviors changed over the course of a 24-week, full-time, paired self-regulated internship program, with each pair mentored by an internship host and a faculty supervisor. Given the long history of internships' role in helping students develop their professional skills, recent work has explored the question of which students access and benefit from internships. Kapoor and Gardner-McCune [11] report that extracurricular experiences and attitudes are critical in students' abilities to find and succeed in internships.

\subsection{Integrating Industry Standards in Undergraduate Programs}

These experiences are particularly important since CS graduates preparing to join industry may confront differences between their academic experience and industry expectations. In an interview with hiring managers, Radermacher et al. [21] identify that a lack of project experience, poor communication skills, or technical deficits could prevent an applicant from being hired. Brechner [1] bemoans recent graduates hired to work at Microsoft who have little experience and skills for coding collaboratively, designing systems that serve their users (with support for accessibility and internationalization), and building functioning code (that is maintainable and scaleable).

Some undergraduate programs address this skills gap via student-led real-world projects and capstone courses [4], or a combination thereof. For example, Oster describes an on-campus software development center where students develop projects for real clients as a way to ramp up their skills to be competitive for industry internships [20]. A the University of Puerto Rico at Mayaguez (UPRM), a program that combines industry internships with undergraduate research has been successful [9]. Internships are one way to allow for industry-level experience and exposure during an undergraduate CS program.

\subsection{Surveys Indicate Students are (Mostly) Happy with Their Internship Experiences}

Students' impressions of the value of internships in various contexts has been reported to be quite positive. Using recruiting to and retention in the CS major as a measure of success, Fryling et al. 
[6] report on a small study where early undergraduate students are offered internship experiences arranged and mentored by faculty after one or two CS courses. Student surveys are a more common way of studying internships. Schambach and Dirks in 2002 [27], Sabag et al. in 2006 [23], and Kapoor and Gardner-McCune in 2019 [10] all used surveys of undergraduate students to solicit their opinions. The survey results indicated significant student satisfaction with their internship experiences. Nonetheless, the researchers report limitations of the survey approach, including potential self-selection bias and potential variations in the styles and intensity of the student internships. In this project, we use qualitative analysis to study the open-ended student reflection on their accomplishments in internships. This analysis allows us to dig deeper on the themes and nuances that explain student satisfaction in these experiences.

\section{PROGRAM STRUCTURE AND PARTICIPANTS}

The project studies the academic component of structured internships taken by a student cohort of 346 undergraduate students majoring in Computer Science and Engineering (CSE) during the Summer 2017 or Summer 2018 intersessions. The 2017 cohort consisted of 237 students, while the 2018 cohort consisted of 109 students. The difference in cohort size reflects institutional and program enrollment cycles.

Before enrolling in the course, students obtained an internship offer for an internship fulfilling all the following criteria: (1) internship projects are related to the CSE major, (2) internship is full-time (at least 30 hours of work each week and at least 8 weeks long), (3) paid, (4) on-site (at the company's place of business; tele-commuting internships do not qualify), and (5) internship is structured with a designated company mentor/supervisor. The course is an upper-division undergraduate level course that can be used toward major and graduation requirements. The course is designed to facilitate students identifying and deepening the connections between their university coursework and real-world problems, and reflecting on the growth of their professional, problemsolving, and technical skills over the internship. To do so, students journal daily and post weekly reflections to a shared discussion board. The students are organized in groups of 4 to 10 students; group members read about each other's experiences and discuss their perspectives on the reflection prompts. The reflection prompts rotate through three main themes for the course: technical development, personal and professional growth, and ethics and society. At the end of the internship (and course), students reflect on their experiences in multiple ways, including surveys and open-ended reflection prompts. In this project, we study student responses to the question "What are you most proud of in this internship?" and consider the ways in which the course themes emerge in the replies.

\section{RESEARCH METHODOLOGY}

We first define the terms we used in our qualitative analysis process.

Internship. To qualify as an internship for this program, internships are required to be fulltime, paid, supervised by a mentor at the organization, and have educational or novel components.

Number of responses. Summative responses to the prompt "What are you most proud of in this internship?" were provided by 297 students.

Internship Organizations. A total of 120 distinct organizations hosted students that participated in the internship program. These organizations spanned multiple sectors and are anonymized for this research. When quoting student reflections that name their internship organization, we replace the name with ANON. 
Internship Locations. $34.2 \%$ of the host organizations were located in the same city in the United States as the academic institution offering the course. Two other cities in the United States known for a high concentration of tech companies represented $34.2 \%$ and $16 \%$ of the internship organizations, respectively. All other regions accounted for less than $10 \%$ of the participating organizations, and included two locations in Asia and one in Europe.

Code. A label that "symbolically assigns a summative, salient, essence capturing" attribute in the data [24].

Major Code. The primary code being examined.

Secondary Code. When reviewing a major code, the next most common code affiliated with this grouping.

Category. A grouping of qualitative codes that documents a pattern. The categories were

- Technical Skills

- Interpersonal Skills

- Ethics and Society

- Academic/Professional Interface

Over the course of a series of meetings, the researchers created and applied codes within each category to describe and quantify the themes emerging in student responses from their final internship reflection. An initial collection of codes was drafted after a sample of student responses was reviewed for common elements. Conversations establishing distinctions between codes continued throughout the coding process.

For the first iteration of coding, the researchers divided the 297 student responses into three parts and each completed an initial pass of holistic coding utilizing ATLAS.ti, a tool that supports qualitative analysis for large datasets. In a calibration meeting after this phase, we focused on clarifying definitions for specific codes that could read as similar. We coded each other's sections and talked through any differing code selections. After the initial round, we also agreed to add an additional code for "Personal growth" within the Interpersonal Skills category. This addition reflected themes that emerged from the student responses that were largely unaccounted for within the established coding structure. After initial coding was completed, the researchers conducted a second cycle of coding of responses, where each analyzed the coding from a different researcher. Any discrepancies were discussed and clarified to create consistent and calibrated interpretations of each code. After the second cycle of coding, a third iteration of coding all responses was conducted by one researcher. The coding process proved to be a cyclical and analytical process [24].

\section{DATA AND RESULTS}

The four categories and their respective codes with the number of student responses are listed below with the summation for each code. Within one student response, there can be several codes, but the same code would not be listed twice for the same response. Since student responses were often assigned multiple codes, the sum of the figures listed does not equal the number of student responses. To visualize the distribution of codes in each category, we include four pie charts in Figure 1.

\subsection{Categories and Codes (Number of Student Responses, \% Among Responses in Category)}

- Technical Skills (447)

- Successful completion of assigned task $(143,32 \%)$

-Use and learn new technologies or tools $(103,23 \%)$ 


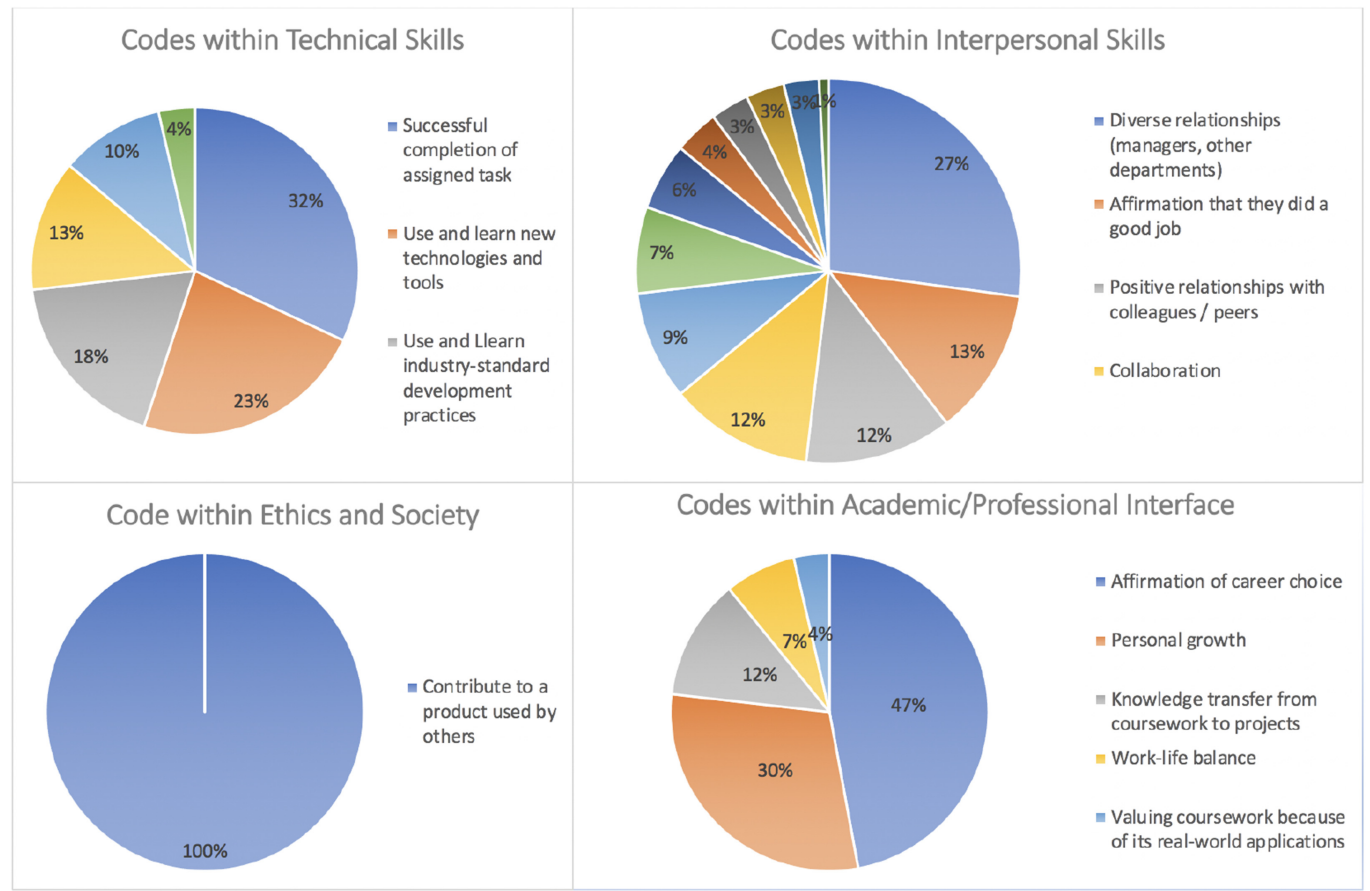

Fig. 1. Distribution of codes in each of the four categories. The most frequent codes are listed in order. The full list of codes, along with their frequencies, are in Section 5.1.

- Use and learn industry-standard development practices $(81,18 \%)$

- Problem solving $(58,13 \%)$

- Large-scale code bases and projects $(46,10 \%)$

- Ability to solve a problem independently $(16,4 \%)$

- Interpersonal Skills (372)

-Diverse relationships (managers, other departments) (101, 27\%)

- Affirmation that they did a good job $(46,12.4 \%)$

- Positive relationships with colleagues/peers $(46,12.4 \%)$

- Collaboration $(45,12 \%)$

- Presentations $(34,9 \%)$

- Persisting through challenges $(27,7 \%)$

- Confidence $(21,6 \%)$

- Time management $(14,4 \%)$

- Help-seeking and asking questions (12, 3\%)

- Receiving and working with feedback $(12,3 \%)$

- Written communication (11,3\%)

- Managing difficult relationships with colleagues/peers (3, 1\%)

-Ethics and Society (91)

- Contribute to product used by others $(91,100 \%)$

- Academic/Professional Interface (138)

- Affirmation of career choice $(65,47 \%)$

- Personal growth $(41,30 \%)$

- Knowledge transfer from coursework to projects $(17,12 \%)$ 
-Work-life balance (10, 7\%)

- Valuing coursework because of its real-world applications (5, 4\%)

The categories and codes mirror the chronology of the course curriculum and were designed to facilitate answering the research question of this project. The first week of coursework is focused on Technical skills, the second week on Interpersonal Skills, and the third week on Ethics and society; these three themes cycled throughout the 12 weeks of the course. A fourth category was added to capture how academic experiences inform and are impacted by professional plans.

Within the category Technical Skills, we distinguished "Diverse relationships" from "Positive relationships with colleagues/peers": the former emphasizes networking with a range of colleagues and the latter captures enjoyable experiences with peers. The code "Large-scale code bases and projects" represented comments on working with sizable datasets from start to finish, whereas the code "Use and learn industry-standard development practices" was used for students who specifically referenced the value of understanding industry norms and practices.

The category Ethics and Society notably has only one code. In responding to the prompt "What are you most proud of in this internship?", we observed that students were more likely to report on their technical or professional growth rather than reflecting on their engagement with ethical issues. Many students did report valuing the impact that their work would have on others (both within their company and beyond), and this was recorded in the code "Contribute to product used by others."

Below, we extract themes and trends that emerged during the analysis. We provide examples for student responses illustrating the coding.

\subsection{An Emphasis on Technical Skills}

Technical Skills was the largest code-set with 447 responses. Within this category, "Successful completion of assigned task" is the most common code from student responses. When students were asked what they are most proud of from their internship, 145 out of 247 students mentioned the successful completion of their assigned task. There was a clear emphasis on the importance of completion with the word "finish" repeated 39 times throughout the student responses:

I finished my whole project, from implementing it and applying for the permission for the onboarding to the deployment to the pipeline.

Several student responses also mentioned the concept of time, noting that their project was completed ahead of or on schedule:

I'm most proud of being able to finish my project and impressing my host. He wasn't sure we'd have enough time to do everything, but we ended up finishing about a week early.

Some of the student responses emphasized their individual accomplishment, while others took pride in collective completion of a project. As an example of individual ownership:

This internship, I am most proud of getting to work on my own full stack project. I got to experience both front end and back end and see how everything all comes together in the end. I even worked on mobile so I feel like I got good exposure all over the stack.

Another student focused on the team effort:

First of all, I learned a new computer language called C\#, and got more and more skillful by the project going on. Besides, the biggest achievement I've accomplished 
is the project itself. Our team members worked hard and united; we helped each other to remove the issues we faced. We presented our product in front of 20 coworkers and college leaders about 2 hours, and gained tremendous success. The applause they gave made me feel proud of our teammates and myself.

The second most frequently applied code also falls under the category of Technical Skills. There were 103 of the 297 student responses coded as Technical Skills: Use and learn new technologies and tools. In these statements, the emphasis is on learning and newness rather than completion. For example:

I was exposed to many different technologies and concepts throughout the internship. We worked on projects ranging from devops to web development and throughout the process had to pick up different concepts ranging from Docker to Django.

Responses in this category reflect an appreciation for the process and learning specific tools.

The third most frequently cited code within the category of Technical Skills, and fifth-most used code in the analysis, was "Use and learn industry-standard development practices." This code was assigned when students spoke to learning or applying industry norms. It was critical to have a subject area expert as a researcher involved in this qualitative analysis in order to identify and label jargon and domain-specific language in responses. This code was almost always paired with other codes and only three responses were solely coded as Technical Skills: Use and Learn IndustryStandard Development Practices. They are:

(1) Became more familiar with good software engineering practices.

(2) I am most proud of the fact that I was able to learn so much about the in's [sic] and out's [sic] of the company.

(3) Although I was learning and understanding the protocols and ways they executed their software development, it was not till the last day that I realized that I was starting to get the hang of things.

\subsection{Developing Interpersonal Skills and Building Relationships}

The most frequently cited code within the category of Interpersonal Skills (and the third most frequent code overall) was "Diverse relationships (managers, other departments)," coding 101 student responses. This code is distinct from the code "Positive relationships with colleagues and peers" in that the emphasis is on the range of relationships formed through their internships, particularly speaking to prospects for future opportunities or commenting on interactions with people at different rungs on the corporate ladder. Common within this code were student responses that indicate that they entered the internship with the purposeful goal to develop their professional network; a typical response is below:

I'm proud of how much I expanded my professional network within these past 10 weeks mostly because my previous internship only gave me a handful of connections in terms of software engineers.

In at least five responses, students identified their development of communication and presentation skills as going hand-in-hand with the growth of their interpersonal skills.

\subsection{Impact-full Development}

Within our four categories, Ethics and Society is the only category with only one code, which is "Contribute to product used by others." This accounts for why this was the smallest category of 
codes (91 responses). However, the code "Contribute to product used by others" was the fourth largest individual code. Responses coded by it spoke of taking pride in their contributions to the organization they were working with and/or to the broader community. Some students spoke to the value of creating something useful:

I am most proud of fulfilling the huge commitment I made to put out a product to customers in a span of three sprints with just basic wireframes in the very beginning. In general, I'm proud of continuously being able to put out things to our customer base in production.

Others directly connected their contribution toward supporting a team:

I was most proud of the fact that I managed to create a meaningful project that made a real impact on the team.

And others presented the broader implications of their work:

I am most proud of having made a tool that will help people after I am gone. It will improve developer productivity and help to make code submissions lower risk by providing a "launch scaling" ability after they have pushed their code.

Another student notes:

The feature won't launch for some time, but when it does, I can say I contributed a little to something that over a billion ANON devices use.

Beyond learning or completion, student responses showed that they were proud of the meaningful contributions they were making, with 13 of these responses using the word "impact."

\subsection{Affirming Career Paths}

The most frequently applied code within the category of Academic/Professional Interface was the sixth-most used overall. Sixty-five student responses noted that the internship provided an "affirmation of career choice;" this could include students speaking to their passion, seeing themselves in this professional setting, and learning more about the reality of the CS industry landscape. An excerpt of a student response to this effect is:

... Overall, I like that I got a chance to undergo the real-world scenario of what I plan to do for a living outside of school...

Many students responded similarly and connected their coursework preparation to practical applications during the internship as a validation of their career choice.

In this section, we described the most frequently observed topics in student responses. We now discuss themes that cut across categories and suggest trends that could be further explored.

\section{DISCUSSION AND AREAS FOR FUTURE RESEARCH}

Student responses captured nuances within and across the described categories and themes that unpack what students were most proud of in their internship experience.

\subsection{Looking Beyond Major Codes}

Certain codes were more frequently paired with other codes. Table 1 lists the second most frequently cited code within the responses from each of the six major codes presented in our results. 
Table 1. Summation of Major Codes and Their Most Common Secondary Codes

\begin{tabular}{|l|l|}
\hline Major Code & Most Common Secondary Code \\
\hline Technical Skills & Ethics and Society \\
Successful completion of assigned task & Contribute to product used by others \\
145 student responses & 32 student responses \\
\hline Technical Skills & Ethics and Society \\
Use and learn new technologies and tools & Successful completion of assigned task \\
103 student responses & 31 student responses \\
\hline Interpersonal Skills & Technical Skills \\
Diverse relationships & Use and learn new technologies and tools \\
101 student responses & 21 student responses \\
\hline Ethics and Society & Technical Skills \\
Contribute to product used by others & Successful completion of assigned task \\
91 student responses & 32 student responses \\
\hline Technical Skills & Technical Skills \\
Use and learn industry-standard development & Use and learn new technologies and tools \\
practices & \\
81 student responses & 27 student responses \\
\hline Academic Professional Interface & Technical Skills \\
Affirmation of career choice & Use and learn industry-standard \\
& development practices \\
65 student responses & 17 student responses \\
\hline
\end{tabular}

Not surprisingly, all the secondary associated codes noted in Table 1 come from the top five most frequently coded responses. Many of the combinations present a natural pairing. For example, students who stated that they were most proud of learning new technologies and tools seem likely to have been successful in using these tools; thus, it is not surprising that many of them are also proud of their ability to complete their assigned task. The combination of these skills reflect valuable professional development for successfully transitioning to industry. One example of a response that reflected new technologies and successful completion of an assigned task is as follows:

The most proud [sic] of my internship is that I implemented ANON, which is a latency and fault tolerance library, into our team project. It can protect the supplier center team's website to isolate points of access to remote systems, services, and 3rd party libraries, stop cascading failure, and enable resilience in complex distributed systems where failure is inevitable.

Among students who stated they were proud of successfully completing an assigned task, the most common secondary code is contributing toward a product used by others. This may reflect a goal orientation, with success measured by completion and impact. For example:

I'm most proud of shipping my service into production. It's nice to see that your work has paid off and will actually be used by the company and not just be unused code.

As this student demonstrates, there is a sense of gratification when contributing toward something that exists beyond an internship and has a lasting impact. 


\subsection{Help-Seeking and the Value of Mentorship}

Many of the student responses represent a great deal of individual and collective accomplishment. Reflecting on how these accomplishments came to pass, we saw much discussion of the value of seeking and receiving help as well as an appreciation of mentorship. For example, this student described a challenging situation where laptops were stolen and files were lost; however, the experience was more manageable with support:

My mentor was with me every step of the way. Normally, he is [at another location], but this week, he and our three other [remote] team members were all in [the office]. Everyone was cheering me on...

Future work could explore how students' perception of help-seeking evolves during their internships. From the "snapshot" we see in this project, many students come to understand the value of asking for help by the end of their internship. It may well be that we could help students realize this earlier with strategic pre-internship assignments or confidence-building exercises.

\subsection{The Role of Embodied Identities in Internship Experiences}

This project analyzed all student responses to a single open-ended prompt at the end of a summer internship to study trends in what students value in their internships. Further research can disaggregate these data based on student demographics, which may inform their internship experiences. For example, students from groups traditionally under-represented in CS as well as first-generation students may have different experiences in and priorities for internships. A large longitudinal study by Seron et al. suggests this might be the case for women in engineering [28]. The National Association of Colleges and Employers (NACE) 2018 Student Survey found that firstgeneration college students who participate in internships are more likely to report benefits from internship experiences than students who are not first in their families to attend post-secondary education, but that their participation rate in internships is lower [26]. The work history and context of internships may also affect student experiences of their benefits. For example, future research could study the impact of team dynamics (was the intern's team working on site or remotely?) and company culture (including size and management style).

\section{IMPLICATIONS FOR THE TEACHING AND LEARNING OF COMPUTING}

\subsection{Scaffolded Reflections as Part of the Computing Internship Experience}

Students participating in the course studied in this article engaged in regular reflections throughout a summer-long industry internship. Consistent self-reflection while in the workplace may help students create more meaningful connections between academic coursework and industry experience. In our study, this was especially apparent in the 65 mentions of students affirming their career choice in their summative reflections. For example: "I had a vague idea of what I wanted to do this summer, but now it cemented my career path." Anecdotally, after the course, multiple students approached the instructor expressing their appreciation for the journaling component of the course. They valued having a record of what they accomplished, both as a source of pride and as a resource in future job searches. They recounted observing their growth from the early journal entries to the end of the summer. In light of this, we encourage other institutions to explore such companion courses supporting students engaged in internships. In addition to scaffolding the onthe-job learning, such a course signals that the student's home academic institution values their internship experience. Making this value explicit may help unify the academic and professional journey of students and frame their learning more holistically. 


\subsection{Practice Motivates Theory}

Undergraduate CS curricula need to balance teaching foundational (older) concepts and keeping up with the latest trends, tools, and frameworks used in industry. Many institutions offer Computer Science or Computer Engineering degrees and are explicitly not bootcamp-style software development programs. As such, many required courses emphasize theory and foundational content. On the other hand, students are often keen to try out cutting-edge skills. Asking students to reflect on the value of the core skills and learning outcomes of their required courses, and to see that the problem-solving and critical thinking they practice in their courses transfer to successful learning on the job, may help alleviate the tension some students feel between what they see in their courses and their pre-conceived notions of what they would be studying. The course studied in this article is structured around three main themes designed to make this knowledge transfer explicit. In the reflections of students participating in the course, we see many mentions of two of these main themes. Technical Skills are mentioned 447 times: students value their technical preparation from courses prior to their internships and value their ability to build on this knowledge and learn on the job. Interpersonal skills are mentioned 372 times: many students see teamwork and interpersonal skills as critical to successfully integrating into the workforce. The weekly reflections built into the companion course for internships encourage conversations about the alignment between academic and industry experiences. We encourage faculty to continue these conversations in the classroom, for example, by explicitly explaining choices to use (or not to use) industry standard tools and processes for course-based projects. Students may be more amenable to more theoretically minded work once its rationale is made explicit and once they have experienced the practical value of the habits of rigorous problem-solving and analytical thinking.

\subsection{Elevating Ethics and Professionalism Conversations}

The course studied in this article includes a deliberate emphasis on Ethics and Society, integrating this theme as one of the recurring coursework topic areas (along with Technical Skills and Interpersonal skills, addressed above). We found 91 mentions of this theme among student reflections, all focusing on "Contribute to product used by others." In particular, many students did not directly address ethics when asked what they were proud of during their internships. In light of the increasingly urgent need for professional computer scientists and engineers to think critically about the ethical foundations of our work due to its potentially widespread and lasting impact, how do we raise the profile of this issue? Internships are often lauded as an integral component of a holistic undergraduate education; internships can complement course curriculum and provide early opportunities for professional development. The course studied in the project allows internships to serve as a vehicle for addressing broader programmatic goals. We recommend continued work to articulate and assess outcomes of this course associated with ethical and professional awareness and decision-making. Currently, students reflecting on their accomplishments mostly had a narrow interpretation of their contributions: "I'm proud of building the foundation for an impactful product." As teachers of CS, we need to continue to work to help our students construct a broad, ethically-minded understanding of what impact means.

\subsection{Opportunities for Curricular Synergy}

At our institution, we've been pleased to see how recognizing the value of industry internships provides fresh opportunities for motivation for students. One low-cost opportunity arises from mining the weekly reflections of interns for real-world examples of applications of core concepts, which can then be shared with students in other classes (with the intern's permission). For example, the anecdote below has been used in a Theory of Computation class to help motivate 
Nondeterministic Finite Automata (NFA), a construct that often appears artificial and abstract to students first learning it:

[The] structure I was using to display the output was a TreeCtrl, so I figured some kind of weird tree traversal system would work, and I made it into this implicit state machine that used a stack to traverse up and down into different levels. In short, it was an absolute monster of a structure (which I am immensely proud of for continuing to work as new requirements were added every couple of hours :p). Needless to say, all that code is now gone.... [Instead,] I designed am [sic] NFA (thanks be ANON INSTRUCTOR OF THEORY CLASS) that could cover every case and also allow the timeline to be completely extensible. Note, I needed an NFA because there are a few input strings that require up to five transitions (the tree gets really deep), and the states couldn't really be just jumped to because of the way the TreeCtrl works. After lunch, I implemented this NFA (as it turns out, there was a slight amount of copy and paste) and had it working and fully functional within an hour. On Wednesday, I arranged a short meeting with my mentor to show it off and discuss some requirements for a side project I was to begin working on. When my mentor showed up to the meeting, he brought with him a ANON COMPANY AWARD for me! ANONs are internal awards given to employees who exceed expectations and provide excellent work (or something like that), and I got one for completing my first project so quickly and saving engineer time.

I FINALLY USED SOMETHING I LEARNED AT ANON UNIVERSITY THAT I NEVER THOUGHT I WOULD USE!!!!! I used ANON THEORY CLASS to design my NFA and knew that an NFA would be a good way to solve this problem only because of that class. Also, that ANON AWARD I got kinda feels like a real world A+, except it actually means something :p.

\section{CONCLUSION}

In answering the research question

In what ways do the themes of technical development, interpersonal skills, ethics and society, and the academic and professional interface emerge when students reflect on their internships?,

we collected students' reflections at the end of intensive summer internships in Computer Science. Many students valued the extent to which they were able to learn on the job and apply this learning to successfully complete the projects assigned to them. Many saw their internships as valuable in expanding their professional network and facilitating their work on projects that would be useful to others. These summer experiences gave many of the students confidence and greater understanding of their career choices. This project contributes a nuanced picture of student values and priorities for successful internships. Employers looking to foster happy potential recruits can use these results in designing their internships. Academic departments can explore ways in which these student priorities can help connect internships with the broader academic program so as to harness the energy and enthusiasm of students returning from their internships. So long as the current technology economy boom continues and internships remain a transformative component of undergraduate education, understanding students' perceptions and priorities can lead to increased success. 


\section{REFERENCES}

[1] Eric Brechner. 2003. Things they would not teach me of in college: What Microsoft developers learn later. In Proceedings of the Companion of the 18th Annual ACM SIGPLAN Conference on Object-oriented Programming, Systems, Languages, and Applications (OOPSLA'03). ACM, New York, NY, 134-136.

[2] Tracy Camp, W. Richards Adrion, Betsy Bizot, Susan Davidson, Mary Hall, Susanne Hambrusch, Ellen Walker, and Stuart Zweben. 2017. Generation CS: The growth of computer science. ACM Inroads 8, 2 (May 2017), 44-50.

[3] Lyn Carson and Kath Fisher. 2006. Raising the bar on criticality: Students' critical reflection in an internship program. fournal of Management Education 30, 5 (2006), 700-723.

[4] C. Dean, T. D. Lynch, and R. Ramnath. 2011. Student perspectives on learning through developing software for the real world. In Frontiers in Education Conference (FIE), 2011. T3F-1-T3F-6.

[5] John Dewey. 1916. Democracy and Education: An Introduction to the Philosophy of Education. Macmillan.

[6] Meg Fryling, MaryAnne Egan, Robin Y. Flatland, Scott Vandenberg, and Sharon Small. 2018. Catch 'em early: Internship and assistantship CS mentoring programs for underclassmen. In Proceedings of the 49th ACM Technical Symposium on Computer Science Education (SIGCSE'18). Association for Computing Machinery, New York, NY, 658-663. DOI : https://doi.org/10.1145/3159450.3159556

[7] Alton R. Goddard. 1974. Relating computer science programs to the needs of industry through internships and cooperative programs. In Proceedings of the 4th SIGCSE Technical Symposium on Computer Science Education (SIGCSE'74). ACM, New York, NY, 165-168.

[8] Matthew T. Hora, Matthew Wolfgram, and Samantha Thompson. 2017. What do we know about the impact of internships on student outcomes? Results from a preliminary review of the scholarly and practitioner literatures. Retrieved from http://ccwt.wceruw.org/documents/CCWT-report-Designing-Internship-Programs.pdf.

[9] M. Jimenez, R. Palomera, and M. Toledo. 2002. Undergraduate research and co-op education: A winning combination. In 32nd Annual Frontiers in Education, Vol. 3. S4C-S4C.

[10] Amanpreet Kapoor and Christina Gardner-McCune. 2019. Understanding CS undergraduate students' professional development through the lens of internship experiences. In Proceedings of the 50th ACM Technical Symposium on Computer Science Education (SIGCSE'19). ACM, New York, NY, 852-858.

[11] Amanpreet Kapoor and Christina Gardner-McCune. 2020. Exploring the participation of CS undergraduate students in industry internships. In Proceedings of the 51st ACM Technical Symposium on Computer Science Education (SIGCSE'20). Association for Computing Machinery, New York, NY, 1103-1109. DOI : https://doi.org/10.1145/3328778 3366844

[12] David A. Kolb. 1984. Experiential Learning: Experience as the Source of Learning and Development. Prentice-Hall, Inc., Englewood Cliffs, N.J.

[13] Jean Lave and Etienne Wenger. 1991. Situated Learning: Legitimate Peripheral Participation. Cambridge University Press.

[14] W. A. Lawrence-Fowler, L. M. Grabowski, and C. F. Reilly. 2015. Bridging the divide: Strategies for college to career readiness in computer science. In Proceedings of the 2015 IEEE Frontiers in Education Conference (FIE). 1-8.

[15] Patrick P. McHugh. 2017. The impact of compensation, supervision and work design on internship efficacy: Implications for educators, employers and prospective interns. Fournal of Education and Work 30, 4 (2017), 367-382.

[16] Mia Minnes, John Mayberry, Melissa Soto, and Jace Hargis. 2017. Practice makes deeper? Regular reflective writing during engineering internships. Journal of Transformative Learning 4, 2 (2017).

[17] Association of American Colleges \& Universities. 2018. High-Impact Educational Practices. Retrieved from https: //www.aacu.org/sites/default/files/files/LEAP/HIP_tables.pdf.

[18] Lih-Bin Oh. 2019. Goal setting and self-regulated experiential learning in a paired internship program. In Proceedings of the ACM Conference on Global Computing Education (CompEd'19). ACM, New York, NY, 239-239.

[19] The Joint Task Force on Computing Curricula Association for Computing Machinery (ACM) IEEE Computer Society. 2013. Computer Science Curricula 2013: Curriculum Guidelines for Undergraduate Degree Programs in Computer Science. Retrieved from https://www.acm.org/binaries/content/assets/education/cs2013_web_final.pdf.

[20] Zachary J. Oster. 2019. Improving access to internships with an on-campus software development center. In Proceedings of the 50th ACM Technical Symposium on Computer Science Education (SIGCSE'19). ACM, New York, NY, 1286-1286.

[21] Alex Radermacher, Gursimran Walia, and Dean Knudson. 2014. Investigating the skill gap between graduating students and industry expectations. In Companion Proceedings of the 36th International Conference on Software Engineering (ICSE Companion 2014). ACM, New York, NY, 291-300.

[22] Julian Riehl. 1983. Intensive internship: A model for improving entry-level systems productivity. In Proceedings of the 20th Annual Computer Personnel on Research Conference (SIGCPR'83). ACM, New York, NY, 113-120. 
[23] N. Sabag, E. Trotskovsky, and P. Schechner. 2006. Internship as an obligatory requirement for the degree of B.Sc. in Electronic and Electrical Engineering. In Proceedings of the 2006 International Conference on Information Technology: Research and Education. 94-98.

[24] J. Saldana. 2015. The Coding Manual for Qualitative Researchers. SAGE Publications. Retrieved from https://books. google.com/books?id=ZhxiCgAAQBAJ.

[25] Jeffrey Saltz and Jae Oh. 2012. An open co-op model for global enterprise technology education: Integrating the internship and course work. In Proceedings of the 43rd ACM Technical Symposium on Computer Science Education (SIGCSE'12). ACM, New York, NY, 117-122.

[26] Angelena Salvadge. 2017. The impact of internships and study abroad on career readiness of first-generation students. Retrieved from https://www.naceweb.org/career-readiness/internships/the-impact-of-internships-andstudy-abroad-on-the-career-readiness-of-first-generation-students/.

[27] Thomas P. Schambach and Jim Dirks. 2002. Student perceptions of internship experiences. In Proceedings of the 17th Annual Conference of the International Academy for Information Management.

[28] Carroll Seron, Susan S. Silbey, Erin Cech, and Brian Rubineau. 2016. Persistence is cultural: Professional socialization and the reproduction of sex segregation. Work and Occupations 43, 2 (2016), 178-214.

[29] Patricia Silva, Betina Lopes, Marco Costa, Ana I. Melo, Goncalo Paiva Dias, Elisabeth Brito, and Dina Seabra. 2018. The million-dollar question: Can internships boost employment? Studies in Higher Education 43, 1 (2018), 2-21.

[30] Janice Tovey. 2001. Building connections between industry and university: Implementing an internship program at a regional university. Technical Communication Quarterly 10, 2 (2001), 225-239.

[31] William L. Ziegler. 1987. Highly structured internship and cooperative education program in computer science. SIGCSE Bulletin 19, 3 (Sept. 1987), 56-64.

[32] Stuart Zweben and Betsy Bizot. 2018. 2018 Taulbee Survey: Undergrad Enrollment Continues Upward; Doctoral Degree Production Declines but Doctoral Enrollment Rises. Retrieved from https://cra.org/wp-content/uploads/2019/ 05/2018_Taulbee_Survey.pdf.

Received January 2020; revised July 2020; accepted September 2020 